\title{
Apparent diffusion coefficient cannot predict molecular subtype and lymph node metastases in invasive breast cancer: a multicenter analysis
}

Alexey Surov ${ }^{1 *}$ D, Yun-Woo Chang ${ }^{2}$, Lihua Li $i^{3}$, Laura Martincich ${ }^{4}$, Savannah C. Partridge ${ }^{5}$, Jin You Kim ${ }^{6}$ and Andreas Wienke $^{7}$

\begin{abstract}
Background: Radiological imaging plays a central role in the diagnosis of breast cancer (BC). Some studies suggest MRI techniques like diffusion weighted imaging (DWI) may provide further prognostic value by discriminating between tumors with different biologic characteristics including receptor status and molecular subtype. However, there is much contradictory reported data regarding such associations in the literature. The purpose of the present study was to provide evident data regarding relationships between quantitative apparent diffusion coefficient (ADC) values on DWI and pathologic prognostic factors in BC.

Methods: Data from 5 centers (661 female patients, mean age, $51.4 \pm 10.5$ years) were acquired. Invasive ductal carcinoma (IDC) was diagnosed in 625 patients (94.6\%) and invasive lobular carcinoma in 36 cases (5.4\%). Luminal A carcinomas were diagnosed in 177 patients (28.0\%), luminal B carcinomas in 279 patients (44.1\%), HER 2+ carcinomas in 66 cases (10.4\%), and triple negative carcinomas in 111 patients (17.5\%). The identified lesions were staged as $\mathrm{T} 1$ in $51.3 \%, \mathrm{~T} 2$ in $43.0 \%, \mathrm{~T} 3$ in 4.2\%, and as $\mathrm{T} 4$ in $1.5 \%$ of the cases. NO was found in $61.3 \%, \mathrm{~N} 1$ in $33.1 \%$, $\mathrm{N} 2$ in $2.9 \%$, and N3 in 2.7\%. ADC values between different groups were compared using the Mann-Whitney $U$ test and by the Kruskal-Wallis $\mathrm{H}$ test. The association between ADC and Ki 67 values was calculated by Spearman's rank correlation coefficient.
\end{abstract}

Results: ADC values of different tumor subtypes overlapped significantly. Luminal B carcinomas had statistically significant lower ADC values compared with luminal $\mathrm{A}(p=0.003)$ and HER $2+(p=0.007)$ lesions. No significant differences of ADC values were observed between luminal A, HER 2+ and triple negative tumors. There were no statistically significant differences of ADC values between different $T$ or $N$ stages of the tumors. Weak statistically significant correlation between ADC and Ki 67 was observed in luminal B carcinoma $(r=-0.130, p=0.03)$. In luminal A, HER 2+ and triple negative tumors there were no significant correlations between ADC and Ki 67.

Conclusion: ADC was not able to discriminate molecular subtypes of $\mathrm{BC}$, and cannot be used as a surrogate marker for disease stage or proliferation activity.

Keywords: Breast cancer, ADC, DWI, Molecular subtype (luminal a, Luminal B, HER 2, Triple negative), Ki 67

\footnotetext{
* Correspondence: Alexey.Surov@medizin.uni-leipzig.de

${ }^{1}$ Department of Diagnostic and Interventional Radiology, University of Ulm,

Albert-Einstein-Allee 23, 89081 Ulm, Germany

Full list of author information is available at the end of the article
}

(c) The Author(s). 2019 Open Access This article is distributed under the terms of the Creative Commons Attribution 4.0 International License (http://creativecommons.org/licenses/by/4.0/), which permits unrestricted use, distribution, and reproduction in any medium, provided you give appropriate credit to the original author(s) and the source, provide a link to the Creative Commons license, and indicate if changes were made. The Creative Commons Public Domain Dedication waiver (http://creativecommons.org/publicdomain/zero/1.0/) applies to the data made available in this article, unless otherwise stated. 


\section{Background}

Breast cancer is a major global health problem and major cause of mortality [1]. In brief, from 2006 to 2010, in non-Hispanic white women, the average annual female breast cancer incidence rate was 127.3 cases per 100,000 females [2]. Approximately 232,340 new cases of invasive breast cancer and 39,620 deaths are expected among US women each year [2]. Furthermore, breast cancer tends to be diagnosed at a younger age than other common cancers, with a median age at diagnosis of 61 years [2]. About 19\% of breast cancers are diagnosed in women ages 30 to 49 years, and $44 \%$ occur among women who are age 65 years or older [3].

Radiological imaging plays a central role in the diagnosis of BC. Furthermore, different imaging modalities, especially magnetic resonance imaging (MRI), can also provide information about histopathology in $\mathrm{BC}$. For example, it has been shown that rim enhancement on dynamic MRI was associated with high expression of proliferation index Ki 67 [4]. Moreover, some reports suggest that diffusion weighted imaging (DWI) may discriminate tumors with varying receptor statuses, with differences in quantitative apparent diffusion coefficient (ADC) values observed between BC subtypes [5-7]. Roknsharifi et al. found that tumors with PR negativity and oncotype score $\geq 18$ (intermediate to high risk for recurrence) demonstrated significantly lower ADC values [5]. Kato et al. reported that the minimum ADC value of Luminal A carcinomas was significantly higher than those of Luminal B tumors $(0.834$ vs. $\left.0.748 \times 10^{-3} \mathrm{~mm}^{2} / \mathrm{s} ; p<0.025\right)$ [6]. Finally, in the study of Sharma et al., triple negative tumors showed a significantly higher ADC compared to non-triple negative cancers [7].

However, according to other authors, ADC cannot discriminate $\mathrm{BC}$ subtypes [8].

Overall, the role of ADC in prediction of several clinically relevant histopathological features in $\mathrm{BC}$ needs to yet be proven because of underlying problems in the current literature. Firstly, the reported data were based only on small number of investigated tumors/patients. Secondly, most of the published studies are retrospective with suitable bias. Thirdly, as mentioned above, the reported data are very contradictory. While some authors found significant correlations between $\mathrm{ADC}$ and histopathology in $\mathrm{BC}$, others did not.

Table $1 \mathrm{MRI}$ techniques used in the centers

\begin{tabular}{|c|c|c|c|}
\hline Centers & MR scanners & DWI sequences and $b$ values & ADC measure \\
\hline 1 & $\begin{array}{l}1.5 \text { T scanner (Sonata, Siemens, } \\
\text { Erlangen, Germany) }\end{array}$ & $\begin{array}{l}\text { Single-Shot Echo Planar sequence: -TR/TE: 5000/ } \\
110 \text { ms, } \\
\text {-FOV: } 320 \mathrm{~mm} \text {, } \\
\text {-matrix: } 128 \times 128, \\
\text {-slice thickness: } 3.5-\mathrm{mm} \text {, } \\
\text { - } 0.7-\mathrm{mm} \text { slice gap, } \\
\text {-b values: } 0-1000 \mathrm{~s} / \mathrm{mm}^{2}\end{array}$ & $\begin{array}{l}\text {-Manual placed multiple ROls; } \\
\text {-measure by one radiologist with } 10 \text { years of } \\
\text { experience in breast imaging; } \\
\text {-cystic or necrotic portions of the tumour were } \\
\text { avoided. }\end{array}$ \\
\hline 2 & $\begin{array}{l}\text { 3.0 T scanner (Magnetom Verio, } \\
\text { Siemens, Germany) }\end{array}$ & $\begin{array}{l}\text { Single-Shot Echo Planar sequence: -TR/TE: 7000/ } \\
85 \text { ms, } \\
\text {-FOV: } 104 \times 320 \mathrm{~mm} \text {, } \\
\text {-matrix } 220 \times 72, \\
\text {-slice thickness: } 6 \mathrm{~mm} \text {; } \\
\text { b values: } 50-1000 \mathrm{~s} / \mathrm{mm}^{2}\end{array}$ & $\begin{array}{l}\text {-Manual placed multiple ROls (whole tumor } \\
\text { measure); } \\
\text {-measure by one radiologist; } \\
\text {-cystic or necrotic portions of the tumour were } \\
\text { avoided. }\end{array}$ \\
\hline 3 & $\begin{array}{l}\text { 1.5 T scanner (GE Healthcare, } \\
\text { Milwaukee, WI, USA) }\end{array}$ & $\begin{array}{l}\text { single-shot echoplanar image: } \\
\text {-TR/TE: } 7000 / 85 \mathrm{~ms} \text {; } \\
\text {-FOV } 340 \times 340 \mathrm{~mm} \text {, } \\
\text {-matrix: } 128 \times 128 \text {, } \\
\text { slice thickness: } 4 \mathrm{~mm} \text {, } \\
\text { b values: } 0-900 \mathrm{~s} / \mathrm{mm}^{2}\end{array}$ & $\begin{array}{l}\text {-Manual placed ROI (single ROI measure); } \\
\text {-measure by one radiologist with } 13 \text { years of } \\
\text { experience in breast imaging; } \\
\text {-cystic or necrotic portions of the tumour were } \\
\text { avoided. }\end{array}$ \\
\hline 4 & $\begin{array}{l}3 \text { T scanner (Achieva Tx, Philips } \\
\text { Healthcare, Best, Netherlands) }\end{array}$ & $\begin{array}{l}\text { single-shot echoplanar image with fat } \\
\text { suppression (spectral attenuated inversion } \\
\text { recovery): } \\
\text {-TR/TE: } 53367000 / 61 \mathrm{~ms} \text {, } \\
\text {-matrix: } 240 \times 240 \text {, } \\
\text {-FOV: } 360 \times 360 \mathrm{~mm} \text {, } \\
\text {-slice thickness: } 5 \mathrm{~mm} \text {, } \\
\text {-b values: } 0-800 \mathrm{~s} / \mathrm{mm}^{2}\end{array}$ & $\begin{array}{l}\text {-Manual placed ROI (single ROI measure); } \\
\text {-measure by one radiologist with } 5 \text { years of } \\
\text { experience in breast MR imaging; } \\
\text {-cystic or necrotic portions of the tumour were } \\
\text { avoided. }\end{array}$ \\
\hline 5 & $\begin{array}{l}3 \mathrm{~T} \text { scanner (Trio Tim, Siemens, } \\
\text { Erlangen, Germany) }\end{array}$ & $\begin{array}{l}\text { Single-Shot Echo Planar sequence: -TR/TE: } 6600 / \\
91 \mathrm{~ms} \text {, } \\
\text { - matrix: } 192 \times 134 \text {, } \\
\text {-FOV: } 320 \times 320 \mathrm{~mm} \text {, } \\
\text {-slice thickness: } 2 \mathrm{~mm} \text {, } \\
\text { b values: } 0-1000 \mathrm{~s} / \mathrm{mm}^{2}\end{array}$ & $\begin{array}{l}\text {-Manual placed ROI (single ROI measure), } \\
\text {-ADC measure by two radiologists with } 5 \text { and } 2 \\
\text { years of experience in breast MRI in consensus, } \\
\text {-cystic or necrotic portions of the tumour were } \\
\text { avoided. }\end{array}$ \\
\hline
\end{tabular}


Table 2 Comparison of tumor ADC values between molecular subtypes

\begin{tabular}{|c|c|c|c|c|c|}
\hline \multicolumn{5}{|l|}{ Tumors } & \multirow[t]{2}{*}{ Kruskal-Wallis test } \\
\hline & $\begin{array}{l}\text { Luminal } A \\
n=177\end{array}$ & $\begin{array}{l}\text { Luminal } B \\
n=279\end{array}$ & $\begin{array}{l}\text { HER 2+, } \\
n=66\end{array}$ & $\begin{array}{l}\text { Triple negative, } \\
n=111\end{array}$ & \\
\hline $\begin{array}{l}\text { ADC values, } \times 10^{-3} \mathrm{~mm}^{2} \mathrm{~s}^{-1} \\
\mathrm{M} \pm \mathrm{SD}\end{array}$ & $\begin{array}{l}1.01 \pm 0.22 \\
p=1.00 \text { Vs HER } 2+\end{array}$ & $\begin{array}{l}\mathbf{0 . 9 5} \pm \mathbf{0 . 2 3} \\
p=0.003 \text { vs luminal } A ; \\
p=0.007 \text { vs HER } 2+\end{array}$ & $\begin{array}{l}1.04 \pm 0.23 \\
p=0.168 \text { vs triple negative }\end{array}$ & $\begin{array}{l}0.95 \pm 0.17 \\
p=0.309 \text { vs luminal } A \\
p=1.00 \text { vs luminal } B\end{array}$ & $P<0.001$ \\
\hline
\end{tabular}

The aim of the present study was to analyze associations between ADC and hormone receptor status in BC in a large multicenter sample.

\section{Methods}

\section{Data acquisition}

This study comprises data from five centers (Table 1) as follows: Department of Radiology, Soonchunhyang University Hospital, Republic of Korea (center 1) [9]; Institute of Biomedical Engineering and Instrumentation, Hangzhou Dianzi University, Hangzhou, China (center 2) [10]; Unit of Radiology, Institute for Cancer Research and Treatment, Turin, Italy (center 3) [11]; Department of Radiology, University of Washington, Seattle, Washington, USA (center 4) [12]; and Department of Radiology, Pusan National University Hospital, Pusan National University School of Medicine and Medical Research Institute, Korea (center 5) [13].
Inclusion criteria were as follows: histopathological diagnosis, available ADC values, hormone receptor status, Ki 67 index, and TNM stage.

\section{Patients, tumors and MRI}

Overall, 661 patients (all female; mean age, 51.4 \pm 10.5 years; median age, 50.5 years; range, $24-85$ years) were included in the study. The histological type of $\mathrm{BC}$ was defined according to the WHO classification [14]. Invasive ductal carcinoma was diagnosed in 625 patients (94.6\%) and invasive lobular carcinoma in 36 cases (5.4\%). There were tumors with different hormone receptor status. The receptor status of the acquired breast carcinomas were classified according to the San Gallen Consensus Meeting [15]. Luminal A carcinomas (i.e. hormone receptor positive carcinomas with a Ki 67 expression < 14\%) were diagnosed in 177 patients $(28.0 \%)$, luminal B carcinomas (i.e. hormone receptor positive

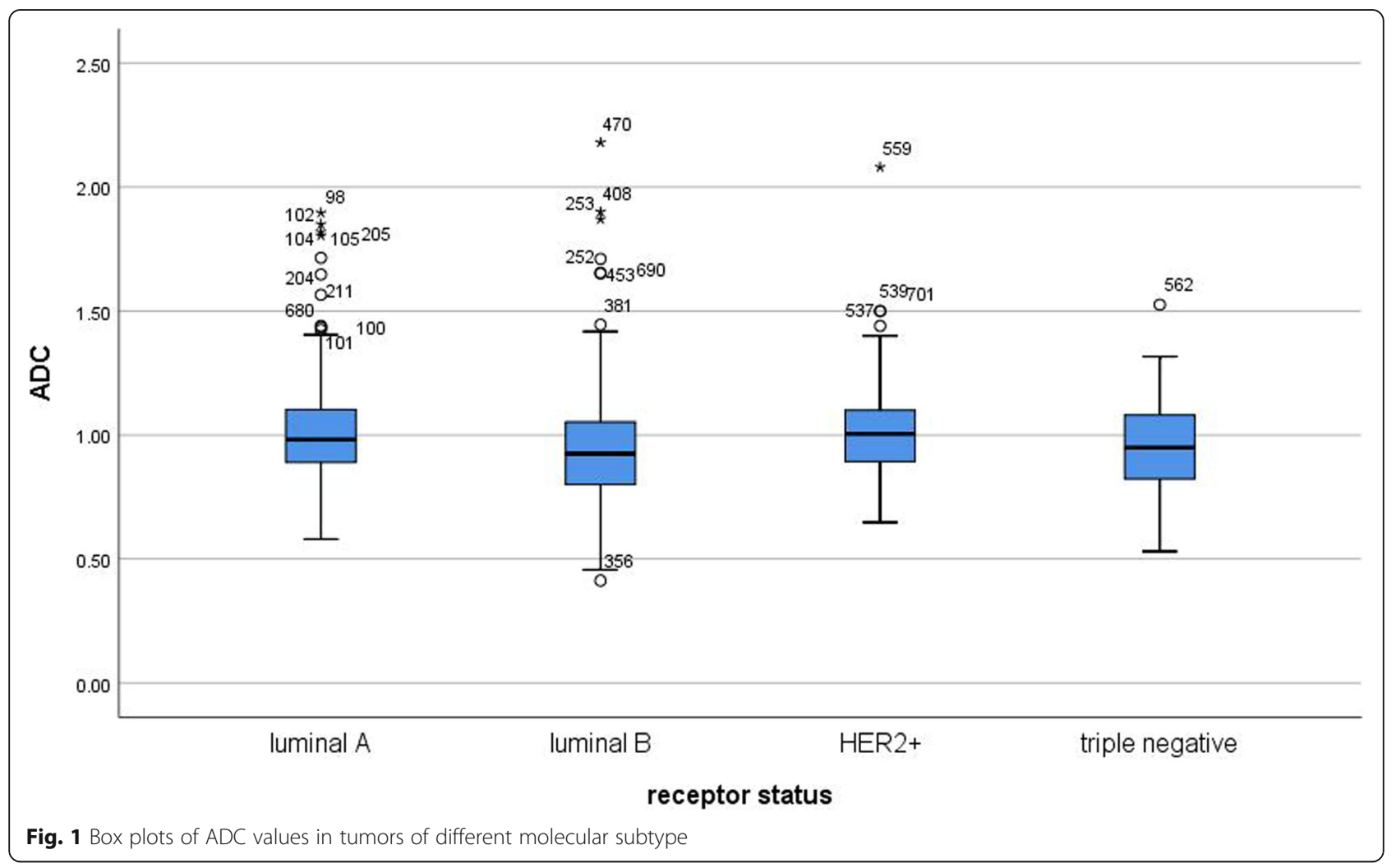




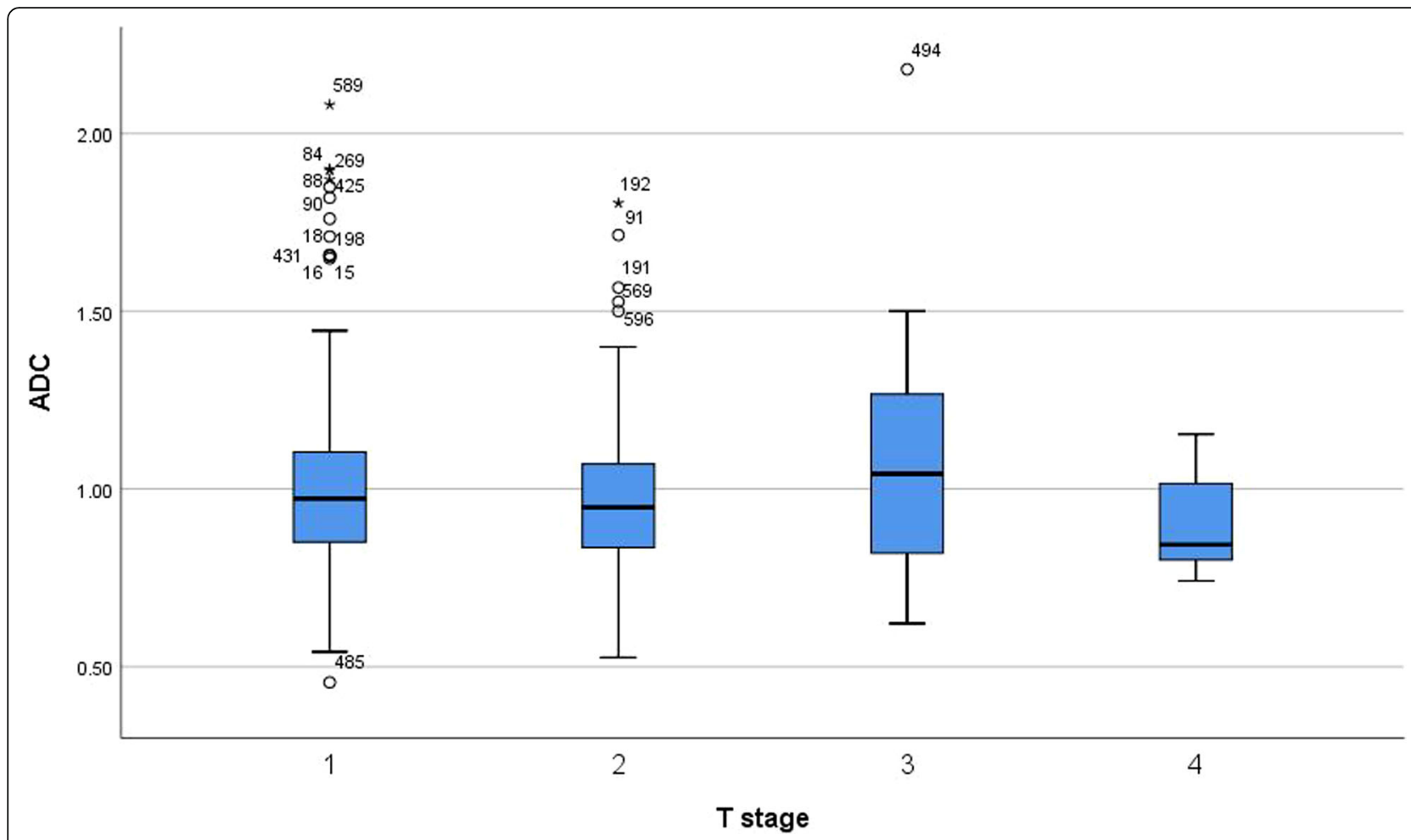

Fig. 2 Box plots of ADC values in different stages of primary tumors. There was no statistical difference between the ADC values (Kruskal-Wallis test $p=0.086)$

tumors with a Ki 67 expression $>14 \%$ ) in 279 patients (44.1\%), HER 2+ carcinomas in 66 cases (10.4\%), and triple negative carcinomas in 111 patients (17.5\%).

Well differentiated (grade 1) BC were diagnosed in 9.9\%, moderately differentiated (grade 2) in $57.9 \%$ and poorly differentiated (grade 3 ) tumors in $32.2 \%$ of the patients. Furthermore, the identified lesions were staged as $\mathrm{T} 1$ in $51.3 \%$, $\mathrm{T} 2$ in $43.0 \%$, $\mathrm{T} 3$ in $4.2 \%$, and as $\mathrm{T} 4$ in $1.5 \%$ of the cases. Regarding N stage, N0 was found in
61.3\%, $\mathrm{N} 1$ in $33.1 \%, \mathrm{~N} 2$ in $2.9 \%$, and $\mathrm{N} 3$ in $2.7 \%$. There were no tumors with distant metastases ( $\mathrm{M}$ stage).

In all cases, MRI with DWI was performed on 1.5 or 3.0 $\mathrm{T}$ clinical scanners with dedicated breast radiofrequency coils (Table 1).

\section{Statistical analysis}

For statistical analysis the SPSS statistical software package was used (SPSS 17.0, SPSS Inc., Chicago IL, USA).
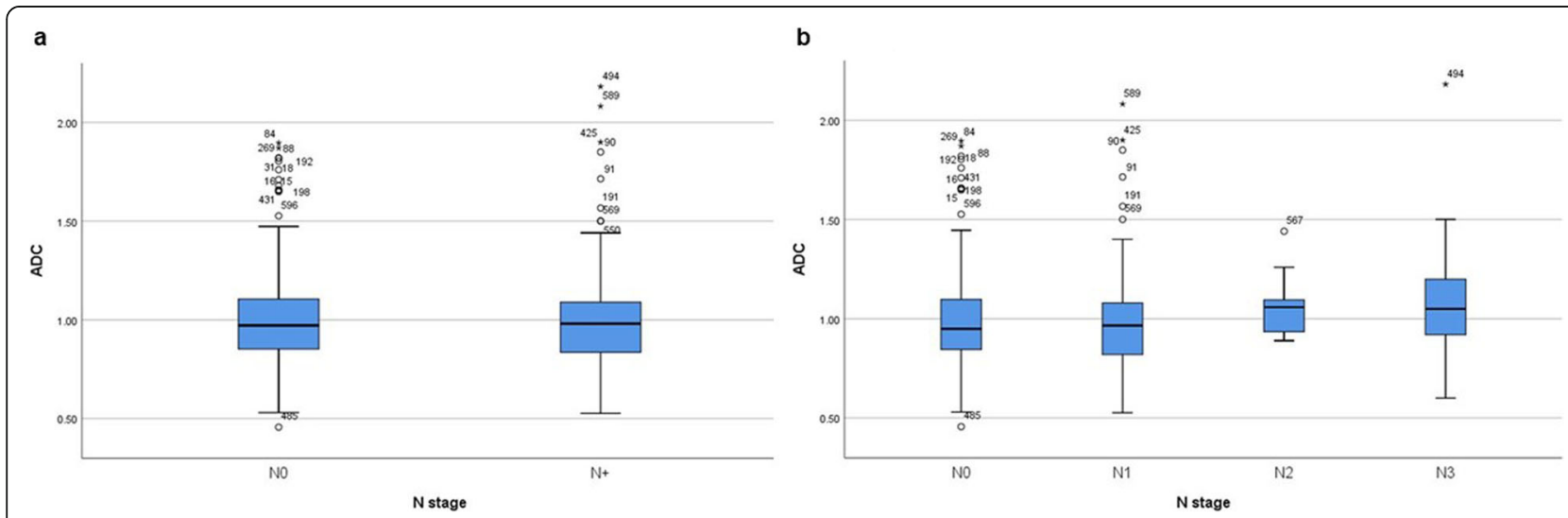

Fig. 3 a Comparison of ADC values between N0 and N+ tumors. No statistical difference between the ADC values was found ( $p=0.849)$. $\mathbf{b}$ Box plots of ADC values in different $N$ stages of breast cancer. There was no statistical difference between the ADC values (Kruskal-Wallis test $p=0.135$ ) 

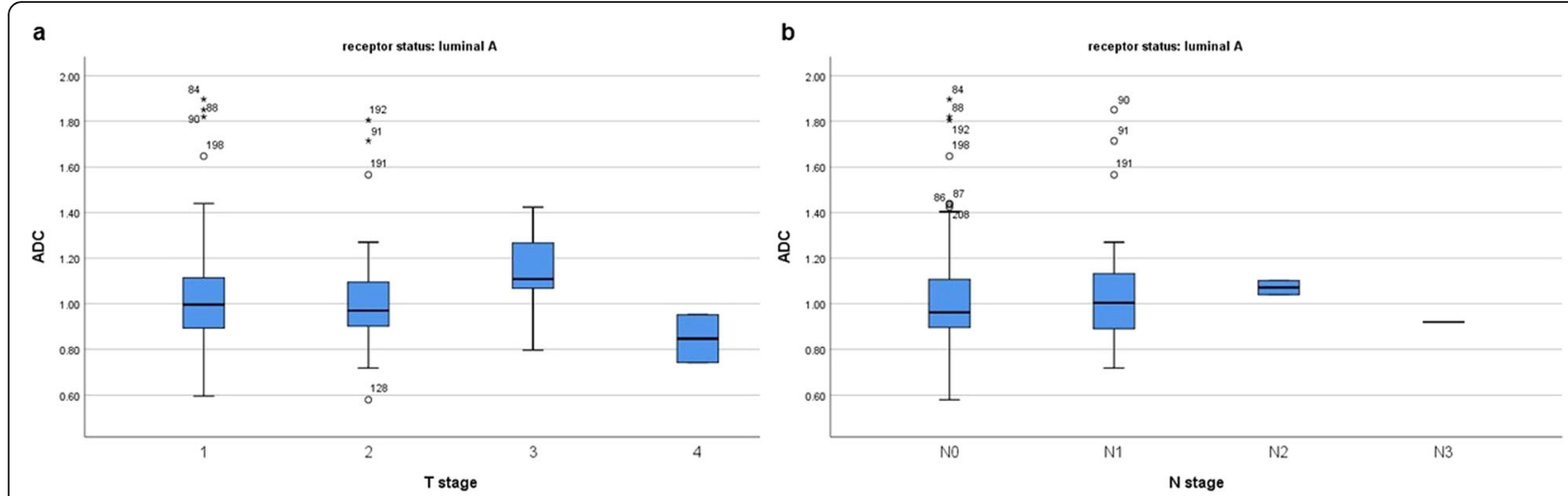

Fig. 4 a Box plots of ADC values in different T stages of luminal A breast cancers. No statistical difference between the ADC values was identified (Kruskal-Wallis test $p=0.313$ ). $\mathbf{b}$ Box plots of ADC values in different $\mathrm{N}$ stages of luminal A breast cancers (Kruskal-Wallis test $p=0.708$ )

Continuous variables were described by mean value, median and standard deviation. Categorical variables were given as relative frequencies. ADC values between different groups were compared using the Mann-Whitney U test (two-group comparisons) and by the Kruskal-Wallis $\mathrm{H}$ test (multiple-group comparisons), where the $p$-values are adjusted for multiple testing (Bonferroni correction). The association between ADC and Ki 67 values was calculated by Spearman's rank correlation coefficient.

\section{Results}

\section{ADC and molecular subtypes}

ADC values differed between tumors of different molecular subtype (Table 2). Luminal B carcinomas had statistically significant lower ADC values compared with luminal A $(p=0.003)$ and HER $2+(p=0.007)$ lesions. However, ADC values of different tumor subtypes overlapped significantly, and no significant differences of
ADC values were observed between luminal A, HER 2+ and triple negative tumors (Fig. 1).

\section{ADC and tumor stage}

There were no statistically significant differences of ADC values between different stages of primary tumors (Fig. 2). Also ADC cannot discriminate NO from $\mathrm{N}+$ tumors (Fig. 3a). In addition, there was no difference of ADC values between N0, N1, N2 and N3 tumors (Fig. 3b).

Furthermore, also in the subgroups with different receptor status ADC could not predict $\mathrm{T}$ and/or $\mathrm{N}$ stage (Figs. 4, 5, 6, 7).

\section{ADC and expression of Ki 67}

In overall sample, ADC correlated weakly with expression of Ki 67 (Table 3). Furthermore, also weak statistically significant correlation between ADC and Ki 67 was observed in luminal $\mathrm{B}$ carcinoma $(r=-0.130, p=0.03)$. In luminal
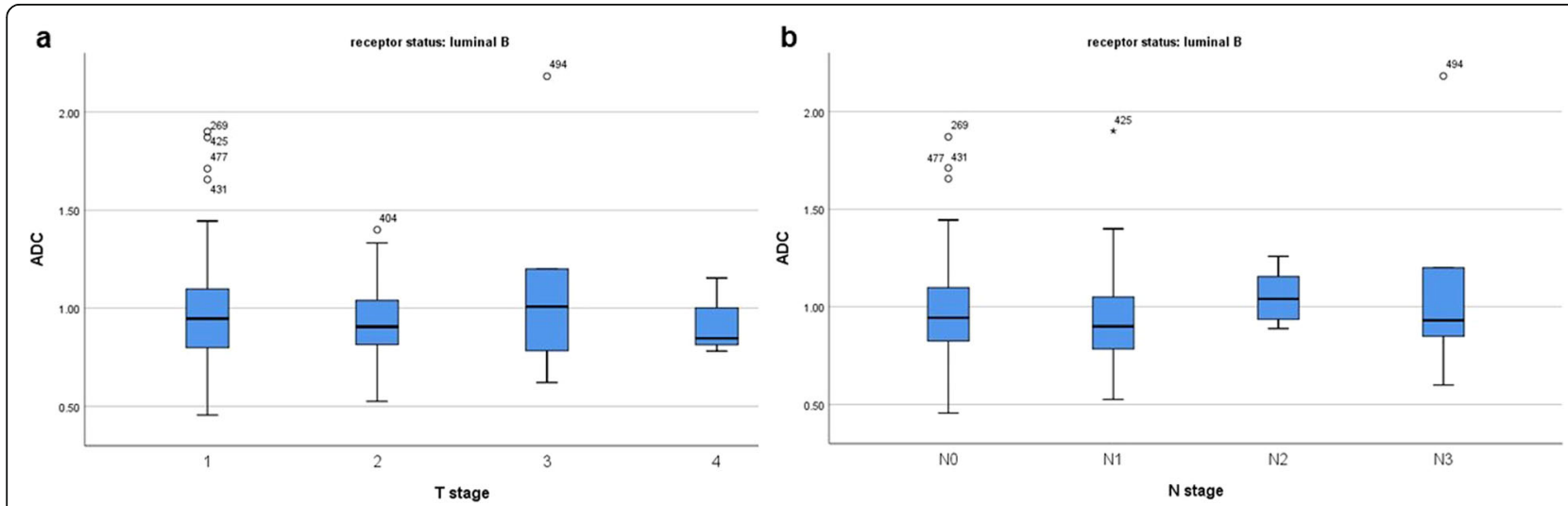

Fig. 5 a Box plots of ADC values in different T stages of luminal B breast cancers (Kruskal-Wallis test $p=0.359$ ). $\mathbf{b}$ Box plots of ADC values in different $\mathrm{N}$ stages of luminal B breast cancers (Kruskal-Wallis test $p=0.090$ ) 

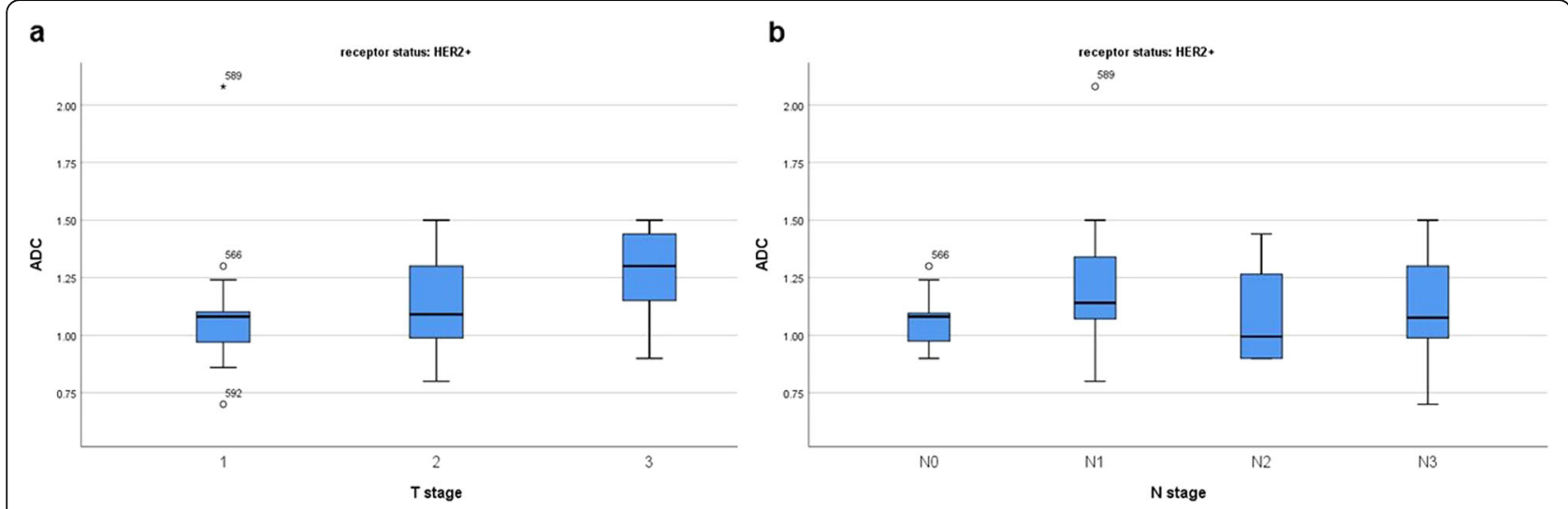

Fig. 6 a Box plots of ADC values in different T stages of HER2+ breast cancers (Kruskal-Wallis test $p=0.233$ ). $\mathbf{b}$ Box plots of ADC values in different N stages of HER2+ breast cancers (Kruskal-Wallis test $p=0.533$ )

A, HER 2+ and triple negative tumors there were no significant correlations between ADC and Ki 67.

\section{Discussion}

To the best our knowledge, this is the first multicenter study evaluating associations between ADC and prognostic pathologic factors in $\mathrm{BC}$.

The possibility to reflect clinically relevant histopathological features may broaden the diagnostic horizon of MRI. If MRI, in particular ADC, can predict histopathology in $\mathrm{BC}$, then $\mathrm{ADC}$ may be used as surrogate biomarker. Consequently, ADC may predict tumor biology and behavior, and, therefore, also tumor prognosis.

DWI measures diffusion of water molecules in tissues [16]. Numerous reports indicated that DWI can reflect several histopathological features of malignant and benign lesions [17-19]. It has been shown that ADC correlated inversely with cell count and proliferation index Ki 67 [17-19]. Furthermore, some authors suggested that ADC may be also associated with expression of epidermal growth factor receptor (EGFR) [20, 21], vascular endothelial growth factor (VEGF) [22], epidermal growth factor receptor 2 (HER2) [23], tumor suppressor protein p53 [20, 21], programmed cell death protein (PD L1) [24], nucleic content [25], and membrane permeability in several tumors [25]. Therefore, it might be possible that ADC may also depend on hormone receptor status in $\mathrm{BC}$. As mentioned above, the results of the previously reported studies comparing ADC and hormone receptor status are contradictory and nondefinitive. However, the present study based on a large multicenter sample showed that ADC cannot really discriminate tumors with different hormone receptor expression. Although, luminal B carcinomas had statistically significant lower $\mathrm{ADC}$ values in comparison to luminal $A$ and HER 2+ BC, ADC values of different tumor subtypes overlapped significantly.

Another interesting aspect of the present study is the fact that ADC of primary tumors cannot predict lymph node status in BC. Previously, some reports indicated
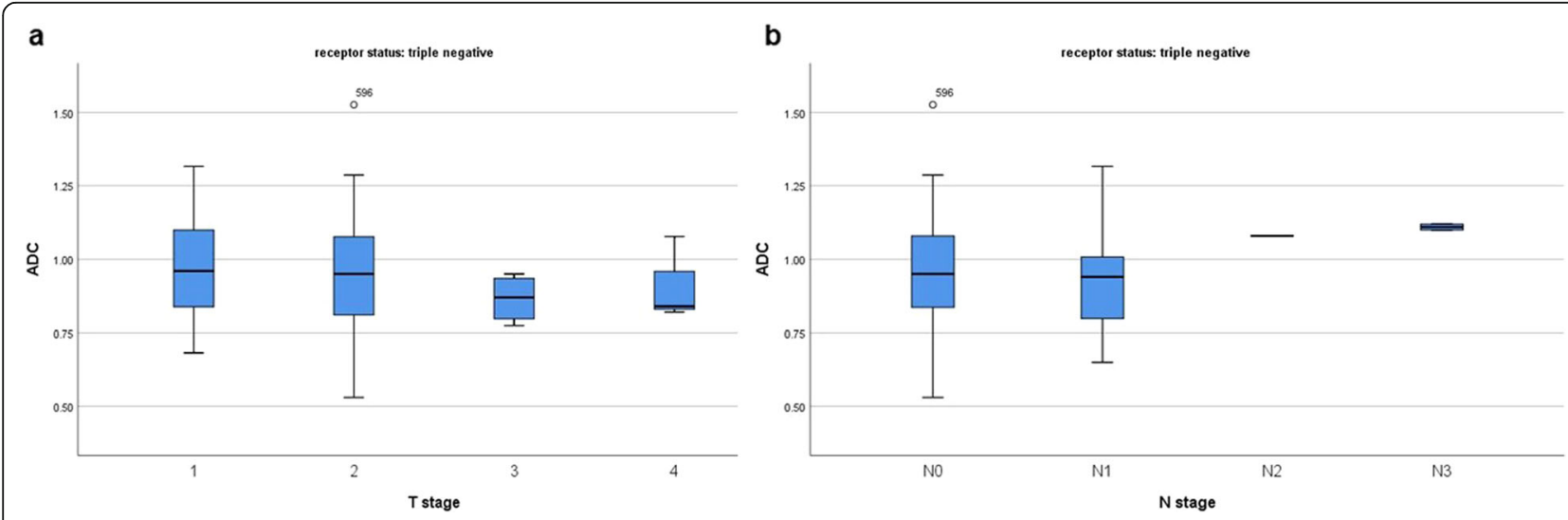

Fig. 7 a Box plots of ADC values in different T stages of triple negative breast cancers (Kruskal-Wallis test $p=0.521$ ). $\mathbf{b}$ Box plots of ADC values in different $\mathrm{N}$ stages of triple negative breast cancers (Kruskal-Wallis test $p=0.205$ ) 
Table 3 Correlation between ADC values and expression of $\mathrm{Ki}$ 67 within molecular subtypes

\begin{tabular}{ll}
\hline Tumors & Correlation coefficients ( $p$ values) \\
\hline Overall sample & $\boldsymbol{r}=\mathbf{- 0 . 1 2 6}(\boldsymbol{p}=\mathbf{0 . 0 0 1 )}$ \\
Luminal A & $r=-0.063(p=0.402)$ \\
Luminal B & $\boldsymbol{r}=-\mathbf{0 . 1 3 0 (} \boldsymbol{p}=\mathbf{0 . 0 3})$ \\
HER 2+ & $r=-0.205(p=0.099)$ \\
Triple negative & $r=0.084(p=0.382)$ \\
\hline
\end{tabular}

Significant correlations are highlighted in bold

that $\mathrm{ADC}$ values of nodal metastasized $\mathrm{BC}$ were lower in comparison to non-metastasized tumors [26-28]. For example, Arponen et al. showed that lower ADC values correlated with presence of axillary metastases $(P=0.03)$ [26]. Our study did not confirm these results.

Similarly, we could not find any associations between $\mathrm{T}$ stage and ADC. This finding is well in agreement with previous reports, which also did not identify correlations between tumor size and ADC values in $\mathrm{BC}[27,29]$.

Analysis of possible relationships between ADC and expression of $\mathrm{Ki} 67$ is also a very important aspect of the present work. Besides hormone receptor, Ki 67 is one of the most clinically important biological markers in $\mathrm{BC}$ and can predict tumor prognosis, disease-free and overall survival [30, 31]. The reported data regarding associations between Ki 67 expression and ADC in BC are controversial. Recently, a large multicenter study could identify only weak correlation between ADC and Ki 67 $(p=-0.202, P<0.001)$ [32]. This finding was in agreement with some meta analyses that also studied correlations between ADC and histopathological findings like proliferation potential and/or tumor cellularity [17, 19]. Therefore, it has been postulated that ADC cannot apply as surrogate biomarker for proliferation activity in $\mathrm{BC}$ [32]. We assumed, however, that different breast carcinomas may also show different associations between ADC and Ki 67. Similar phenomenon was previously identified in meningiomas [33]. Also in $\mathrm{BC}$, it has been shown that different carcinoma subtypes namely invasive ductal carcinomas, invasive lobular carcinomas and ductal carcinoma in situ had different correlations between ADC and Ki 67 [32]. Furthermore, Mori et al. found that the mean $\mathrm{ADC}$ values correlated statistically significant $(r=-0.55$, $P<0.0001)$ with Ki 67 in luminal BC [29]. However, according to Onishi et al., ADC did not correlate statistically significant $(r=0.035, P=0.892)$ with $\mathrm{Ki} 67$ in mucinous BC [34].

In fact, the present study showed that only in luminal B subtype ADC correlated statistically significant with $\mathrm{Ki}$ 67. However, the identified correlations were weak. In other subtypes, namely luminal A, HER 2+ and triple negative $\mathrm{BC}$, no significant associations between the parameters were found.
There are some limitations to address. Firstly, this is a retrospective analysis. Secondly, different MR scanners with different technical parameters like field strength (Tesla), DWI sequences, and b values were used in different centers. Thirdly, the tumor cohort consisted predominantly of invasive ductal carcinomas. Furthermore, our cohorts had smaller number of HER $2+$ tumors in comparison to other subtypes.

All the mentioned factors may influence our results. However, our study is the largest to date and, therefore, provides evident data regarding associations between $\mathrm{ADC}$ and clinically relevant biological parameters in $\mathrm{BC}$. Furthermore, our data reflects a real clinical situation.

\section{Conclusions}

The present multicenter study showed that ADC is not able to discriminate molecular subtypes of $\mathrm{BC}$, and cannot be used as a surrogate marker for disease stage or proliferation activity.

\section{Abbreviations \\ ADC: apparent diffusion coefficient; BC: breast cancer; DWI: diffusion weighted imaging; MRl: magnetic resonance imaging}

\section{Acknowledgements}

None

\section{Authors' contributions}

AS made substantial contributions to conception and design, or acquisition of data, or analysis and interpretation of data; AW, YWC, LL, LM, SCP, JYK been involved in drafting the manuscript or revising it critically for important intellectual content; AW, YWC, LL, LM, SCP, JYK given final approval of the version to be published. Each author should have participated sufficiently in the work to take public responsibility for appropriate portions of the content: and AS, AW, YWC, LL, LM, SCP, JYK agreed to be accountable for all aspects of the work in ensuring that questions related to the accuracy or integrity of any part of the work are appropriately investigated and resolved.

\section{Funding}

None

\section{Availability of data and materials}

The data that support the findings of this study are available from professor Surov but restrictions apply to the availability of these data, which were used under license for the current study, and so are not publicly available. Data are however available from the authors upon reasonable request and with permission of professor Surov.

\section{Ethics approval and consent to participate}

Not applicable

\section{Consent for publication}

Not applicable

\section{Competing interests}

The authors declare that they have no competing interests.

\section{Author details}

${ }^{1}$ Department of Diagnostic and Interventional Radiology, University of UIm, Albert-Einstein-Allee 23, 89081 Ulm, Germany. Department of Radiology, Soonchunhyang University Hospital, 59 Daesakwan-ro, Yongsan-gu, Seoul 140-743, Republic of Korea. ${ }^{3}$ Institute of Biomedical Engineering and Instrumentation, Hangzhou Dianzi University, Hangzhou, China. ${ }^{4}$ Unit of Radiology, Institute for Cancer Research and Treatment (IRCC), Strada Provinciale 142, 10060 Candiolo, Turin, Italy. ${ }^{5}$ Department of Radiology, 
University of Washington, Seattle, Washington 825 Eastlake Ave. E, G2-600, Seattle, WA 98109, USA. ${ }^{6}$ Department of Radiology, Pusan National University Hospital, Pusan National University School of Medicine and Medical Research Institute 1-10, Ami-Dong, Seo-gu, Busan 602-739, South Korea. ${ }^{7}$ Institute of Medical Epidemiology, Biostatistics, and Informatics, Martin-Luther-University Halle-Wittenberg, Magdeburger Str, 06097 Halle, Germany.

Received: 8 May 2019 Accepted: 27 October 2019

\section{Published online: 05 November 2019}

\section{References}

1. Barrios CH, Reinert T, Werutsky G. Global breast Cancer research: moving forward. Am Soc Clin Oncol Educ Book. 2018;38:441-50.

2. DeSantis CE, Lin CC, Mariotto AB, et al. Cancer treatment and survivorship statistics, 2014. CA Cancer J Clin. 2014;64:252-71.

3. Miller KD, Siegel RL, Lin CC, Mariotto AB, Kramer JL, Rowland JH, Stein KD, Alteri R, Jemal A. Cancer treatment and survivorship statistics, 2016. CA Cancer J Clin. 2016;66(4):271-89.

4. Szabo BK, Aspelin P, Kristoffersen Wiberg M, Tot T, Bone B. Invasive breast cancer: correlation of dynamic MR features with prognostic factors. Eur Radiol. 2003;13(11):2425-35.

5. Roknsharifi S, Fishman MDC, Agarwal MD, Brook A, Kharbanda V, Dialani V. The role of diffusion weighted imaging as supplement to dynamic contrast enhanced breast MRI: Can it help predict malignancy, histologic grade and recurrence? Acad Radiol. 2018 S1076-6332(18)30426-4. doi: https://doi.org/ 10.1016/j.acra.2018.09.003.?

6. Kato F, Kudo K, Yamashita H, Wang J, Hosoda M, Hatanaka KC, Mimura R, Oyama-Manabe N, Shirato H. Differences in morphological features and minimum apparent diffusion coefficient values among breast cancer subtypes using 3-tesla MRI. Eur J Radiol. 2016;85(1):96-102.

7. Sharma U, Sah RG, Agarwal K, Parshad R, Seenu V, Mathur SR, Hari S, Jagannathan NR. Potential of diffusion-weighted imaging in the characterization of malignant, benign, and healthy breast tissues and molecular subtypes of breast Cancer. Front Oncol. 2016;6:126. https://doi. org/10.3389/fonc.2016.00126 eCollection 2016.

8. Aydin H, Guner B, Esen Bostanci I, Bulut ZM, Aribas BK, Dogan L, Gulcelik MA. Is there any relationship between adc values of diffusion-weighted imaging and the histopathological prognostic factors of invasive ductal carcinoma? Br J Radiol. 2018;91(1084):20170705.

9. Choi SY, Chang YW, Park HJ, Kim HJ, Hong SS, Seo DY. Correlation of the apparent diffusion coefficiency values on diffusion-weighted imaging with prognostic factors for breast cancer. Br J Radiol. 2012;85(1016):e474-9.

10. Fan M, He T, Zhang P, Zhang J, Li L. Heterogeneity of diffusion-weighted imaging in Tumours and the surrounding Stroma for prediction of Ki-67 proliferation status in breast Cancer. Sci Rep. 2017;7(1):2875.

11. Martincich L, Deantoni V, Bertotto I, Redana S, Kubatzki F, Sarotto I, Rossi V, Liotti M, Ponzone R, Aglietta M, Regge D, Montemurro F. Correlations between diffusion-weighted imaging and breast cancer biomarkers. Eur Radiol. 2012;22(7):1519-28.

12. Amornsiripanitch N, Nguyen VT, Rahbar H, Hippe DS, Gadi VK, Rendi MH, Partridge SC. Diffusion-weighted MRI characteristics associated with prognostic pathological factors and recurrence risk in invasive ER+/HER2- breast cancers. J Magn Reson Imaging. 2017. https://doi.org/10.1002/jmri.25909.

13. Shin JK, Kim JY. Dynamic contrast-enhanced and diffusion-weighted MRI of estrogen receptor-positive invasive breast cancers: associations between quantitative MR parameters and Ki-67 proliferation status. J Magn Reson Imaging. 2017:45(1):94-102.

14. Lakhani, SR, Ellis. IO, Schnitt SJ, Tan PH, van de Vijver MJ. World Health Organization classifcation of tumor of the breast: IARC; 2012.

15. Goldhirsch A, Wood WC, Coates AS, Gelber RD, Thürlimann B, Senn HJ; panel members. Strategies for subtypes-dealing with the diversity of breast cancer: highlights of the St. Gallen international expert consensus on the primary therapy of early breast Cancer 2011. Ann Oncol 2011;22(8):1736-1747.

16. Harkins KD, Galons J-P, Secomb TW, Trouard TP. Assessment of the effects of cellular tissue properties on ADC measurements by numerical simulation of water diffusion. Magn Reson Med. 2009;62:1414-22.

17. Surov A, Meyer HJ, Wienke A. Correlation between apparent diffusion coefficient (ADC) and cellularity is different in several tumors: a Metaanalysis. Oncotarget. 2017;8:59492-9.
18. Surov A, Meyer HJ, Wienke A. Correlation between minimum apparent diffusion coefficient (ADCmin) and tumor cellularity: a meta-analysis. Anticancer Res. 2017;37:3807-10.

19. Surov A, Meyer HJ, Wienke A. Correlation between apparent diffusion coefficient (ADC) and KI 67 in different tumors: a Meta-analysis. Part 1: ADCmean. Oncotarget. 2017:8(43):75434-44.

20. Meyer HJ, Leifels L, Hamerla G, Höhn AK, Surov A. ADC-histogram analysis in head and neck squamous cell carcinoma. Associations with different histopathological features including expression of EGFR, VEGF, HIF-1a, her 2 and p53. A preliminary study. Magn Reson Imaging. 2018;54:214-7.

21. Meyer HJ, Gundermann P, Höhn AK, Hamerla G, Surov A. Associations between whole tumor histogram analysis parameters derived from ADC maps and expression of EGFR, VEGF, Hif 1-alpha, her-2 and histone 3 in uterine cervical cancer. Magn Reson Imaging. 2018;57:68-74.

22. Ma T, Yang S, Jing H, Cong L, Cao Z, Liu Z, Huang Z. Apparent diffusion coefficients in prostate cancer: correlation with molecular markers Ki-67, HIF-1a and VEGF. NMR Biomed. 2018;31(3). https://doi.org/10.1002/nbm.3884.

23. Ji C, Zhang Q, Guan W, Guo T, Chen L, Liu S, He J, Zhou Z. Role of intravoxel incoherent motion MR imaging in preoperative assessing HER2 status of gastric cancers. Oncotarget. 2017;8(30):49293-302.

24. Meyer HJ, Höhn AK, Surov A. Histogram analysis of ADC in rectal cancer: associations with different histopathological findings including expression of EGFR, Hif 1alpha, VEGF, p53, PD 1, and KI 67. A preliminary study. Oncotarget. 2018;9(26):18510-7.

25. Surov A, Hamerla G, Meyer HJ, Winter K, Schob S, Fiedler E. Whole lesion histogram analysis of meningiomas derived from ADC values. Correlation with several cellularity parameters, proliferation index KI 67, nucleic content, and membrane permeability. Magn Reson Imaging. 2018;51:158-62.

26. Arponen O, Sudah M, Masarwah A, Taina M, Rautiainen S, Könönen M, Sironen R, Kosma VM, Sutela A, Hakumäki J, Vanninen R. Diffusion-Weighted Imaging in 3.0 Tesla Breast MRI: Diagnostic Performance and Tumor Characterization Using Small Subregions vs. Whole Tumor Regions of Interest. PLoS One. 2015;10(10):e0138702.

27. Belli P, Costantini M, Bufi E, Giardina GG, Rinaldi P, Franceschini G, Bonomo L. Diffusion magnetic resonance imaging in breast cancer characterisation: correlations between the apparent diffusion coefficient and major prognostic factors. Radiol Med. 2015;120(3):268-76.

28. Igarashi T, Furube $H$, Ashida $H$, Ojiri H. Breast MRI for prediction of lymphovascular invasion in breast cancer patients with clinically negative axillary lymph nodes. Eur J Radiol. 2018;107:111-8.

29. Mori N, Ota H, Mugikura S, Takasawa C, Ishida T, Watanabe G, Tada H, Watanabe M, Takase K, Takahashi S. Luminal-type breast cancer: correlation of apparent diffusion coefficients with the Ki-67 labeling index. Radiology. 2015;274(1):66-73.

30. Petrelli F, Viale G, Cabiddu M, Barni S. Prognostic value of different cut-off levels of Ki-67 in breast cancer: a systematic review and meta-analysis of 64,196 patients. Breast Cancer Res Treat. 2015;153(3):477-91.

31. Kontzoglou K, Palla V, Karaolanis G, Karaiskos I, Alexiou I, Pateras I, Konstantoudakis K, Stamatakos M. Correlation between Ki67 and breast cancer prognosis. Oncology. 2013;84(4):219-25.

32. Surov A, Clauser P, Chang YW, Li L, Martincich L, Partridge SC, Kim JY, Meyer $\mathrm{HJ}$, Wienke A. Can diffusion weighted imaging predict tumor grade and expression of $\mathrm{KI} 67$ in breast cancer? A multicenter analysis. Breast Cancer Res. 2018;20(1):58.

33. Surov A, Gottschling S, Mawrin C, Prell J, Spielmann RP, Wienke A, Fiedler E. Diffusion-weighted imaging in meningioma: prediction of tumor grade and association with Histopathological parameters. Transl Oncol. 2015;8(6):517-23.

34. Onishi N, Kanao S, Kataoka M, lima M, Sakaguchi R, Kawai M, Kataoka TR, Mikami Y, Toi M, Togashi K. Apparent diffusion coefficient as a potential surrogate marker for Ki-67 index in mucinous breast carcinoma. J Magn Reson Imaging. 2015;41(3):610-5.

\section{Publisher's Note}

Springer Nature remains neutral with regard to jurisdictional claims in published maps and institutional affiliations. 